\title{
Effects of MSC Coadministration and Route of Delivery on Cord Blood Hematopoietic Stem Cell Engraftment
}

\author{
S. Carrancio, $* \dagger+$ C. Romo, $* \dagger \neq$ T. Ramos, ${ }^{*} \dagger$ N. Lopez-Holgado, $* \dagger$ S. Muntion, $* \dagger$ H. J. Prins,, \\ A. C. Martens, $\S$ J. G. Briñón,đI J. F. San Miguel, $*+\neq$ M. C. del Cañizo, $*+\neq$ and F. Sanchez-Guijo* $* \neq$ \\ *Servicio de Hematología, IBSAL-Hospital Universitario de Salamanca, Salamanca, Spain \\ $†$ Centro en Red de Medicina Regenerativa y Terapia Celular de Castilla y León \\ and Red Nacional de Terapia Celular (Tercel, ISCIII), Salamanca, Spain \\ ¥Centro de Investigación del Cáncer-IBMCC (Universidad de Salamanca-CSIC), Salamanca, Spain \\ §Department of Immunology and Department of Cell Biology, University Medical Center Utrecht, Utrecht, The Netherlands \\ IIDepartamento de Biologia Celular y Patologia, Universidad de Salamanca, Salamanca, Spain
}

\begin{abstract}
Hematopoietic stem cell transplantation (HSCT) using umbilical cord blood (UCB) progenitors is increasingly being used. One of the problems that may arise after UCB transplantation is an impaired engraftment. Either intrabone (IB) injection of hematopoietic progenitors or mesenchymal stem cell (MSC) coadministration has been proposed among the strategies to improve engraftment. In the current study, we have assessed the effects of both approaches. Thus, NOD/SCID recipients were transplanted with human UCB CD34 ${ }^{+}$cells administered either intravenously (IV) or IB, receiving or not bone marrow (BM)-derived MSCs also IV or IB (in the right femur). Human HSC engraftment was measured 3 and 6 weeks after transplantation. Injected MSCs were tracked weekly by bioluminescence. Also, lodgment within the BM niche was assessed at the latter time point by immunofluorescence. Our study shows regarding HSC engraftment that the number of BM human CD45+ cells detected 3 weeks after transplantation was significantly higher in mice cotransplanted with human MSCs. Moreover, these mice had a higher myeloid $\left(\mathrm{CD} 13^{+}\right)$engraftment and a faster B-cell $\left(\mathrm{CD} 19^{+}\right)$chimerism. At the late time point evaluated (6 weeks), human engraftment was higher in the group in which both strategies were employed (IB injection of HSC and MSC coadministration). When assessing human MSC administration route, we were able to track MSCs only in the injected femurs, whereas they lost their signal in the contralateral bones. These human MSCs were mainly located around blood vessels in the subendosteal region. In summary, our study shows that MSC coadministration can enhance HSC engraftment in our xenogenic transplantation model, as well as IB administration of the $\mathrm{CD} 34^{+}$cells does. The combination of both strategies seems to be synergistic. Interestingly, MSCs were detected only where they were IB injected contributing to the vascular niche.
\end{abstract}

Key words: Mesenchymal stem cells (MSCs); Cordon blood transplantation; Bone marrow microenvironment; Hematopoietic engraftment

\section{INTRODUCTION}

Hematopoietic stem cell transplantation (HSCT) using umbilical cord blood (UCB) is increasingly being used in order to treat malignant or nonmalignant hematologic diseases $(24,31,32,41)$. UCB-HSCT is a suitable procedure in pediatric patients, but in adults, the hematopoietic recovery is slower than with bone marrow $(\mathrm{BM})$ or peripheral blood (PB) transplantation (56). In a number of cases, engraftment is impaired or even absent, mainly because of the lower cellular dose, but other factors such as impaired microenvironment after intensive doses of chemoradiotherapy may also contribute to this $(16,42)$. In order to increase hematopoietic recovery in the UCB transplantation setting, several approaches have been designed $(16,42)$. Ex vivo expansion of hematopoietic stem cells (HSCs) has been proposed as a feasible method, but graft improvement has been hampered by HSC exhaustion in most experimental conditions $(18,50)$. The use of a double cord blood unit transplantation (DCBT) has shown faster engraftment when compared to single-unit transplant, but limitations remain for a number of reasons $(25,45)$. A third approach has been the infusion of thirdparty donor-mobilized HSCs, T-cells depleted, along with UCB transplantation as a "bridge engraftment" strategy till the engraftment of the latter, but their results are still very preliminary (10). 
Two additional methods have been recently proposed: direct intrabone (IB) transplantation of UCB cells (22) or the coadministration of mesenchymal stem cells (MSCs) along with HSCs $(30,37)$. The faster hematopoietic recovery with the first proposed method could be due to a better stem cell homing, preventing the cell loss observed when cells are infused intravenously (IV) (3).

The second approach is based on the fact that BM MSCs contribute to most cell types involved in BM HSC niches (36). They regulate BM homeostasis by cell-tocell contact and through cytokine production (36). Also, these cells have shown immunomodulatory and antiinflammatory properties $(33,47)$. These properties make them an attractive therapeutic tool in UCB transplantation setting to enhance engraftment. Although several studies have been designed to investigate MSC capability to enhance hematopoietic engraftment as well as the mechanisms involved, controversial information has been published about their migration, engraftment capacity, and function after in vivo injection $(17,37)$.

In this study, we have compared both procedures, IB administration of UCB cells and MSC injection in an animal model, in order to ascertain whether one of them or both could ameliorate hematopoietic engraftment.

\section{MATERIALS AND METHODS}

\section{MSC Isolation, Expansion, and Characterization}

Human MSCs were isolated from BM cells of 20 healthy volunteer donors (11 males/9 females) with a median age of 43 years (range, 25-49 years) after informed consent had been obtained, in accordance with the local ethics committee of the University Hospital of Salamanca. Ten to $20 \mathrm{ml}$ of BM were taken by iliac crest aspiration under local anesthesia according to standard institutional procedures. Mononuclear cells (MNCs) were isolated by Ficoll-Paque density gradient centrifugation (GE Healthcare BioSciences, Uppsala, Sweden) and resuspended in Dulbecco's modified Eagle's medium-low glucose (DMEM) (Gibco, Invitrogen, Paisley, UK) supplemented with $10 \%$ fetal calf serum (FCS) (BioWhittaker, Lonza, Verviers, Belgium) and $1 \%$ penicillin/streptomycin (Gibco), as previously reported $(5,46)$. Cells were seeded at an initial density of $10^{6}$ cells $/ \mathrm{cm}^{2}$ and incubated in a humidified atmosphere with 5\% $\mathrm{CO}_{2}$. MSCs were expanded in T75 culture flasks (Corning, Corning, NY, USA) and expanded as previously described. After the third passage, MSCs were assessed following the minimal criteria recommended by the International Society for Cellular Therapy (ISCT) (9). Differentiation capacity to osteoblast, adipocytes, and chondrocytes was done using NH Osteodiff Medium, NH Adipodiff Medium, and NH Chondrodiff Medium, respectively (Miltenyi Biotec, Bergisch Gladbach, Germany), as previously described (5). For immunophenotypic analysis,
MSCs were incubated for 15 min with fluorescein isothiocyanate (FITC)-conjugated cluster of differentiation 90 (CD90), FITC-conjugated CD44, FITC-conjugated CD34, phycoerythrin (PE)-conjugated CD73, PE-conjugated CD14, PE-conjugated CD166, phycoerythrin-cyanine 5 (PC5)-conjugated anti-human leukocyte antigen (HLA)DR, PC5-conjugated CD45, and PC5-conjugated CD19 (all from Becton Dickinson Biosciences, San Jose, CA, USA) and allophycocyanine (APC)-conjugated CD105 (R\&D Systems, Minneapolis, MN, USA). Measurements were made on a FACSCalibur flow cytometer (Becton Dickinson Biosciences). Data were analyzed using the Infinicyt program (Cytognos, Salamanca, Spain), as previously described (8).

\section{CD34 ${ }^{+}$Cell Selection}

A total of 20 fresh human UCB units (from 9 male and 11 female subjects) were obtained from the Barcelona Blood and Tissue Bank according to their ethical rules. Eighty to $100 \mathrm{ml}$ of heparinized cord blood was diluted in phosphate-buffered saline (PBS; Gibco). MNCs were isolated by Ficoll-Paque density gradient centrifugation, and then $\mathrm{CD}_{34}{ }^{+}$progenitor cells were isolated by magnetic labeling using the human CD34 MicroBead Kit (Milteny Biotec) in accordance with the manufacturer's protocol. After isolation, the purity of $\mathrm{CD} 34^{+}$cells was evaluated by flow cytometry using FITC-conjugated CD34 (Becton Dickinson Biosciences).

\section{Lentiviral Vector}

For the lentiviral vector (LV) used in this study, a 1.7-kb Luc2 fragment was isolated from pGL4.10(luc2) vector (Promega, Madison, WI, USA) using $\mathrm{XhoI}$ and $\mathrm{Xba \textrm {I }}$ restriction sites. Subsequently, this Luc2 fragment was cloned in the LV pRRL central polypurine tract cytomegalovirus internal ribosome entry site green fluorescent protein woodchuck hepatitis virus posttranscriptional regulatory element self-inactivating vector [pRRL-cPPT-CMV-IRESGFPPRE-SIN, kindly provided by Prof. Hoeben, Leiden University Medical Center, Leiden, The Netherlands (4)] using the same restriction sites, downstream of the CMV promoter, to generate pRRL-cPPT-CMV-Luc2IRESGFP-PRE-SIN. Expression of the luciferase gene driven by the CMV promoter was confirmed with in vitro assays $(11,12)$.

\section{Transfection of Virus-Producing Cells}

For virus production, $2 \times 10^{6}$ human embryonic kidney (HEK) 293T cells (kindly provided by Prof. J. P. Bolaños, from the University of Salamanca, Spain) were seeded on a 15-cm diameter culture dishes (BD Falcon, San Jose, CA, USA) 1 day before transfection and maintained in DMEM supplemented with $10 \%$ FCS and the antibiotics penicillin $(100 \mathrm{U} / \mathrm{ml})$ and streptomycin $(0.1 \mathrm{mg} / \mathrm{ml})$. Briefly, 
293T cells were transfected with the envelope vector pLVvesicular stomatitis Indiana virus $\mathrm{G}$ protein (VSVG), the packaging vector psPax2, and the LV vector containing the luciferase (Luc2) gene pRRL-cPPT-CMV-IRES-GFPPRE-SIN by using the calcium phosphate DNA precipitation method, as previously described (15). The medium containing lentiviral supernatant was collected at $48 \mathrm{~h}$ after transfection, filtered through a $0.45-\mu \mathrm{m}$ pore filter $(\mathrm{BD}$ Falcon), pooled, and stored at $-80^{\circ} \mathrm{C}$ until use. The titer of the virus supernatant was estimated by transducing $293 \mathrm{~T}$ cells with different dilutions, and the transduction efficiency was determined by flow cytometry analysis of GFP. Titer was calculated using the following formula: (cell concentration at the day of transduction $) \times($ virus supernatant dilution $) \times(\%$ GFP-positive cells $) /$ total volume.

\section{MSC Transduction}

Passage 2 MSCs were transduced when a 50\% confluence of the stromal layer was observed. Transductions were carried out in the presence of $8 \mu \mathrm{g} / \mathrm{ml}$ of hexadimethrine bromide (polybrene; Sigma-Aldrich, Steinheim, Germany) and 1:8 LV supernatants, resulting in a multiplicity of infection of 1.5 . After $24 \mathrm{~h}$, the transduction medium was replaced with a fresh medium. At $90 \%$ confluence, cells were harvested, and $\mathrm{GFP}^{+}$cells were analyzed by flow cytometry to determine transduction efficiency. The multiplicity of infection (MOI) used in this experiment was 1.5 , resulting in a transduction efficiency of the MSCs of $>70 \%$ on the basis of GFP expression analyzed by flow cytometry.

\section{Transplantation of NOD/SCID Mice}

Six-week-old nonobese diabetic severe combined immunodeficient (NOD/SCID; NOD.CB17-Prkdc scid/NcrCrl) mice were purchased from Charles River Laboratories (Barcelona, Spain), housed in microisolator cages, and maintained under sterile conditions in the animal facility of the University of Salamanca. All procedures followed the Spanish and European Union guidelines (RD 1201/05 and $86 / 609 / \mathrm{CEE}$, respectively) and were approved by the Bioethics Committee of the University of Salamanca (reg. no. 201100007924). The NOD/SCID mouse transplant model was established as reported previously with modifications (20). A total of 100 female mice were used for these experiments ( 20 per experimental group). Six to $8 \mathrm{~h}$ before transplantation, animals were exposed to $300 \mathrm{cGy}$ total body irradiation from a cesium (CS) source (Gammacell200, Nordion International, Ottawa, ON, Canada). In this study, the IV or intrabone (IB) injection as well as the coadministration of MSCs were combined to test their effect on hematopoietic engraftment according to the following transplantation groups: (1) $10^{5} \mathrm{IV}$ CD34+ cells; (2) $10^{5} \mathrm{IV}$ CD $34^{+}$cells and $5 \times 10^{5}$ IB MSCs; (3) $10^{5}$ IV CD34+ cells and $5 \times 10^{5}$ IV MSCs; (4) $10^{5}$ IB CD34+ cells; (5) $10^{5} \mathrm{IB}$ $\mathrm{CD} 4^{+}$cells and $5 \times 10^{5}$ IB MSCs. Before transplantation, animals were anesthetized with a mixture of ketamine (90 mg/kg; Imalgene 500, Merial, Lyon, France) and xylazine $(10 \mathrm{mg} / \mathrm{kg}$; Rompun 2\%, KVP Pharma, Bayer Healthcare, Kiel, Germany). For IV injection, cells were resuspended in a total volume of $200 \mu \mathrm{l}$ of PBS and slowly injected by tail vein. For IB injection, cells were injected through the knee into the femur in a total volume of $20 \mu \mathrm{l}$ of PBS. Animals were transplanted with MSCs from an adult donor and HSCs from a pool of three to four different UCB units, being all units from same sex donor for each pool. There were sex mismatches between HSC and MSC donors. Hematopoietic engraftment was evaluated by flow cytometry at weeks 3 and 6 after transplantation in peripheral blood (PB), injected femur (right femur), and contralateral femur (left femur) samples (52). Six weeks after transplantation, mice were killed, and their femurs were fixed in $4 \%$ formaldehyde (Panreac, Barcelona, Spain) for immunohistological analysis.

\section{Analysis of Human Hematopoietic Engraftment by Flow Cytometry}

For flow cytometry studies, PB was obtained from mice eye vein and BM samples from both femurs. All cell suspensions were collected in PBS, subjected to red cell lysis by treatment with ammonium chloride, washed once, and then resuspended again in PBS. To analyze human hematopoietic cells engraftment, samples were stained with FITC-conjugated anti-human CD45 (Miltenyi Biotec). For multilineage detection, cells were stained with APCconjugated CD3, PE-conjugated CD13, PE-conjugated CD14, and APC-conjugated CD19 (all from Becton Dickinson Biosciences). In all cases, 10 min before acquisition, samples were stained with 7-amino-actinomycin D (7-AAD; Becton Dickinson Biosciences). An unstained control was also included for each sample. For data analysis, hematopoietic cells were gated by forward/side scatter to exclude potential contamination with GFP-transduced MSCs. Then, CD45 expression was used to gate human cells and 7AAD to exclude dead cells. Finally, human hematopoietic subpopulations were detected by CD3 (T-cells), CD13 (myeloid cells), CD14 (monocytes), and CD19 (B-cells) expression within the human $\mathrm{CD} 45^{+}$live gate. In addition, as previously indicated, a control unstained sample was acquired in each study of $\mathrm{PB}$ or BM, and rare unspecific positive event (if any) values were subtracted to the values of the positive events for each marker.

\section{In Vivo Bioluminescence}

In order to track the mesenchymal population in vivo, bioluminescence images (BLI) were acquired weekly using a Xenogen IVIS 50 (Caliper Life Sciences, Alameda, CA, USA) bioluminescence/fluorescence optical imaging system at different time points. A few minutes before BLI, the mice were anesthetized with isoflurane (1-3\%) (Forane, 
Abbot Laboratories, Madrid, Spain). Mice were given the substrate D-luciferin (150 mg/kg in PBS) (Promega) by intraperitoneal injection. Ten minutes after administration of substrate, the anesthetized mice were placed onto the warmed stage inside the light tight camera box with continuous exposure to isoflurane (1-2\%). After acquiring photographic images of mice, luminescent images were acquired with 2-min exposure times. Exposure conditions (time, aperture, stage position, binning, and time after injection) were kept identical in all measurements. For quantification, standard regions of interest (ROIs) were defined for femurs and lungs separately. Measurements were expressed as photons per second. The resulting gray scale photographic and pseudocolor luminescent images were automatically superimposed so that identification of any optical signal with location on the mouse was facilitated. Optical images were displayed and analyzed with IVIS Living Image (Caliper Life Sciences) software packages.

\section{Immunohistochemistry}

Femurs were fixed, decalcified for $24 \mathrm{~h}$, and embedded in paraffin, and 5- $\mu \mathrm{m}$-thick tissue sections were placed on glass slides. The sections were then incubated with 5\% normal donkey serum and bovine serum albumin to block nonspecific binding. In order to detect cells from human origin, a primary antibody for human mitochondria detection (Millipore, Billerica, MA, USA) was used. For detection of human MSCs, endogenous GFP signals were amplified by staining sections with rabbit anti-GFP antibody (AbCam, Cambridge, UK). As secondary antibody, Alexa Fluor448-conjugated anti-rabbit IgG and Alexa555 anti-mouse $\mathrm{IgG}$ were used (both from Invitrogen). After washes, $1 \mu \mathrm{g} / \mathrm{ml} \mathrm{4}$ ',6-diamidine-2'-phenyl indole, dihydrochloride (DAPI; Sigma-Aldrich) in PBS was added, and the cells were incubated at room temperature for 5 min. Slides were viewed with a Leica DMI6000B fluorescence microscope (Leica Microsystems $\mathrm{GmbH}$, Wetzlar, Germany) equipped with camera system.

\section{Statistical Analysis}

Median and ranges were calculated for each variable. To estimate the significance of the differences between the groups, the nonparametric Mann-Whitney $U$ test was used. As a result of multiple subgroup assessments, a modified
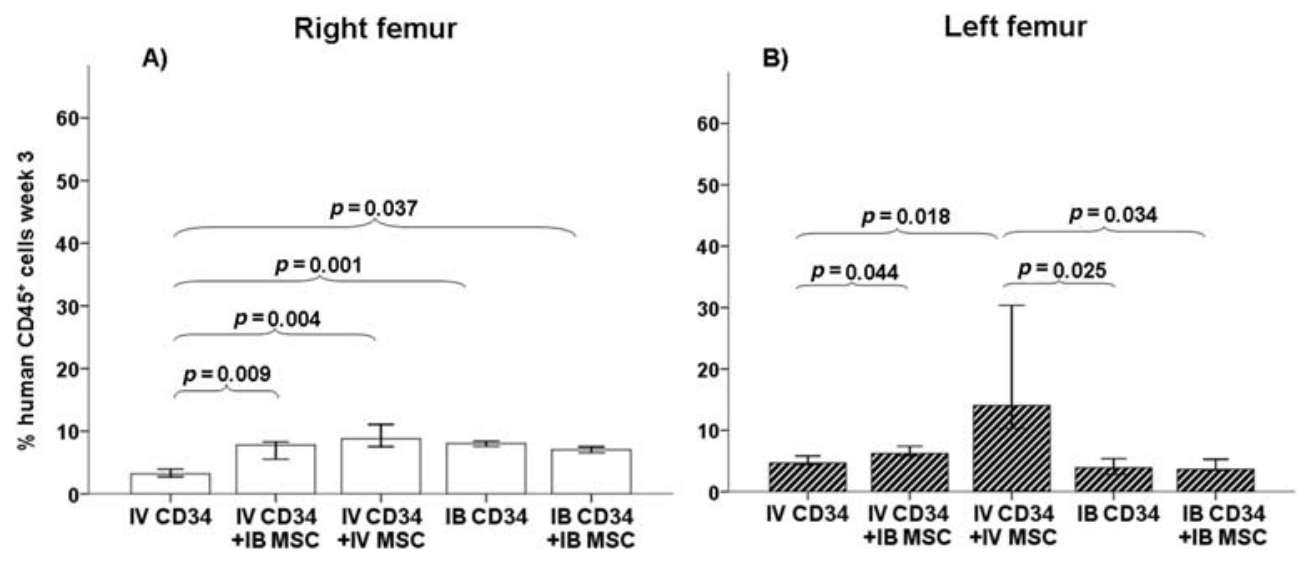

c)
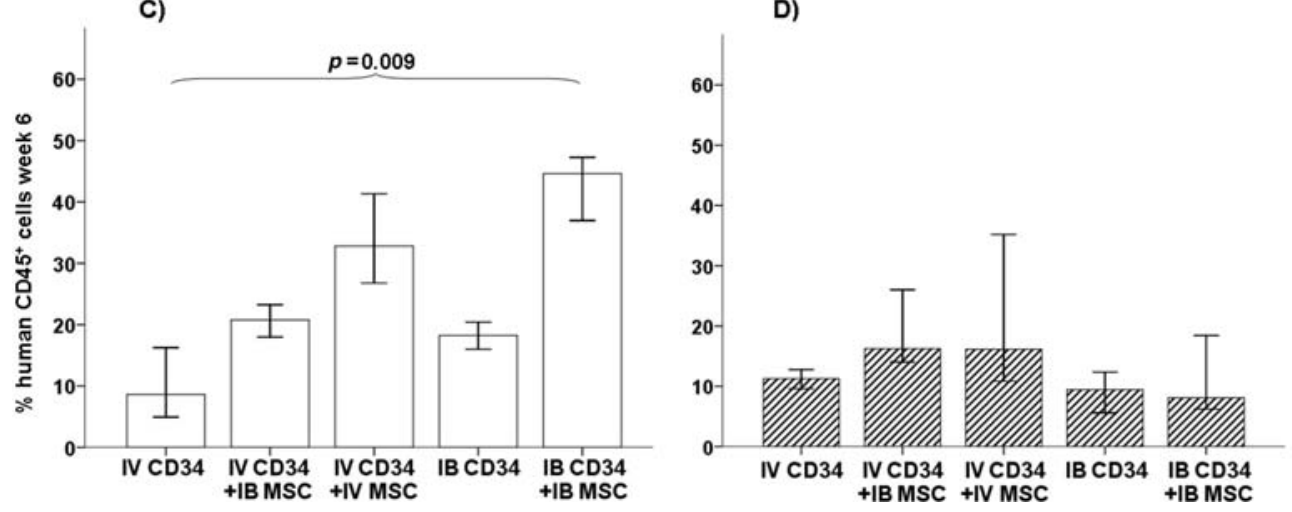

Figure 1. Human hematopoietic engraftment in nonobese diabetic/severe combined immunodeficient (NOD/SCID) bone marrow. Percentage of human $\mathrm{CD} 45^{+}$cells in bone marrow samples from both femurs, right (A, C) (injected site) and left (contralateral) (B, D), at $3(\mathrm{~A}, \mathrm{~B})$ and $6(\mathrm{C}, \mathrm{D})$ weeks after transplantation. Results expressed as medians (range). IV, intravenous injection; IB, intrabone injection in right femur; CD34, human $\mathrm{CD} 34^{+}$cells; MSC, mesenchymal stem cells. 

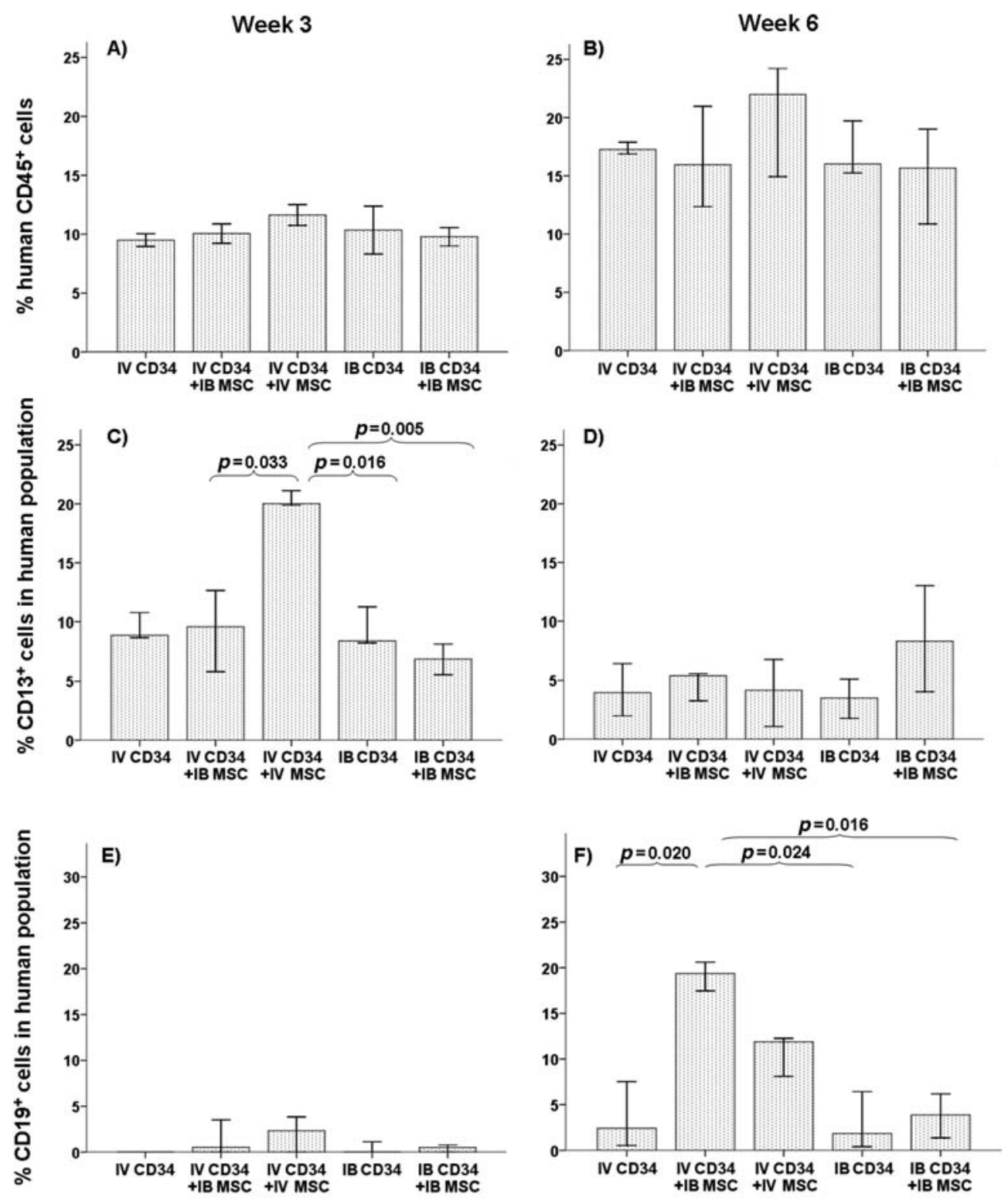

Figure 2. Human hematopoietic cells in NOD/SCID peripheral blood. Percentage of human CD45 in total mononuclear cells in peripheral blood (A, B) as well as percentage of myeloid CD13 ${ }^{+}$cells $(\mathrm{C}, \mathrm{D})$ and lymphoid CD19 ${ }^{+}$cells $(\mathrm{E}, \mathrm{F})$ into the human population at $3(\mathrm{~A}, \mathrm{C}, \mathrm{E})$ and $6(\mathrm{~B}, \mathrm{D}, \mathrm{F})$ weeks after transplantation. Results are expressed as medians (range). IV, intravenous injection; IB, intrabone injection in right femur; CD34, human CD34+ cells; MSC, mesenchymal stem cells.

Bonferroni correction $(\alpha / 5)$ was used to adjust the $p$ value. Differences were considered to be significant for values of $p<0.05$. All statistical analyses were done with SPSS 17.0 (Chicago, IL, USA).

\section{RESULTS}

MSCs from BM samples were expanded in all cases. All of them adhered to plastic surfaces; were capable of differentiating into adipocytes, osteoblasts, and chondrocytes; expressed the antigens CD44, CD73, CD90, CD105, and CD166; and were negative for hematopoietic antigens following the criteria defined by the ISCT (9) for MSC use. In all cases, we were able to transduce MSCs. Transduction efficiency of the MSCs was $>70 \%$ on the basis of GFP expression analyzed by flow cytometry (data not shown).

$\mathrm{CD} 34^{+}$cells were isolated from all UCB samples. Cell purity was above $85 \%$ in all cases.

\section{Human Hematopoietic Engraftment}

In order to test the optimal transplantation combination, human hematopoietic engraftment was analyzed in NOD/SCID mice. Human cells were detected in all cases 
by flow cytometry. Mice receiving only IV CD34 were used as controls.

Human engraftment was expressed as percentage of human $\mathrm{CD}^{4} 5^{+}$cells present among the total number of BM or PB MNCs (Fig. 1). Regarding the injected femur (right), 3 weeks after transplantation (Fig. 1A), higher human hematopoietic cells were observed in all new combinations when compared with $\mathrm{CD} 34^{+}$cells IV injection. The highest percentage of human chimerism was observed in mice receiving IV infusion of both cell types (MSCs and CD34+ cells). Regarding left femurs only mice receiving IV, CD34+ cells together with MSCs showed a higher human hematopoietic chimerism than other groups, independent of the injection route of MSCs (Fig. 1B).

Six weeks after transplantation (Fig. 1C, D), the highest BM human engraftment was observed in mice which had received MSCs and $\mathrm{CD} 4^{+}$cells by IB injection (Fig. 1C). In the left femur, no differences were observed at week 6 (Fig. 1D).
When percentage of human $\mathrm{CD} 45^{+}$cells was analyzed in PB (Fig. 2), no differences among the different study groups and time points were observed (Fig. 2A, B).

In order to analyze the engraftment of myeloid cells, monocytes, B- and T-cells, $\mathrm{CD}_{13}{ }^{+}, \mathrm{CD}_{14}{ }^{+}, \mathrm{CD}_{19}{ }^{+}$, and $\mathrm{CD}^{+}$cell subsets were determined, respectively, within the human $\mathrm{CD} 45^{+}$cell population.

At week 3, when PB was evaluated, only the group receiving both cell types intravenously showed higher level of human myeloid cells (Fig. 2C). Also, CD19+ cells were only detected in MSC-receiving groups (Fig. 2E). Six weeks after transplantation, in PB, the groups with HSCs IV and MSCs showed higher level of lymphoid cells (Fig. 2F).

At 3 weeks, in BM, the majority of human cells showed CD13 expression with similar number of positive cells in all groups (Fig. 3A, B). CD19+ cells were mainly detected in MSC-receiving groups (Fig. 3C, D) producing higher differences with no MSC groups.

In the latest period, in BM, the percentage of myeloid cells among human population was decreased, while the
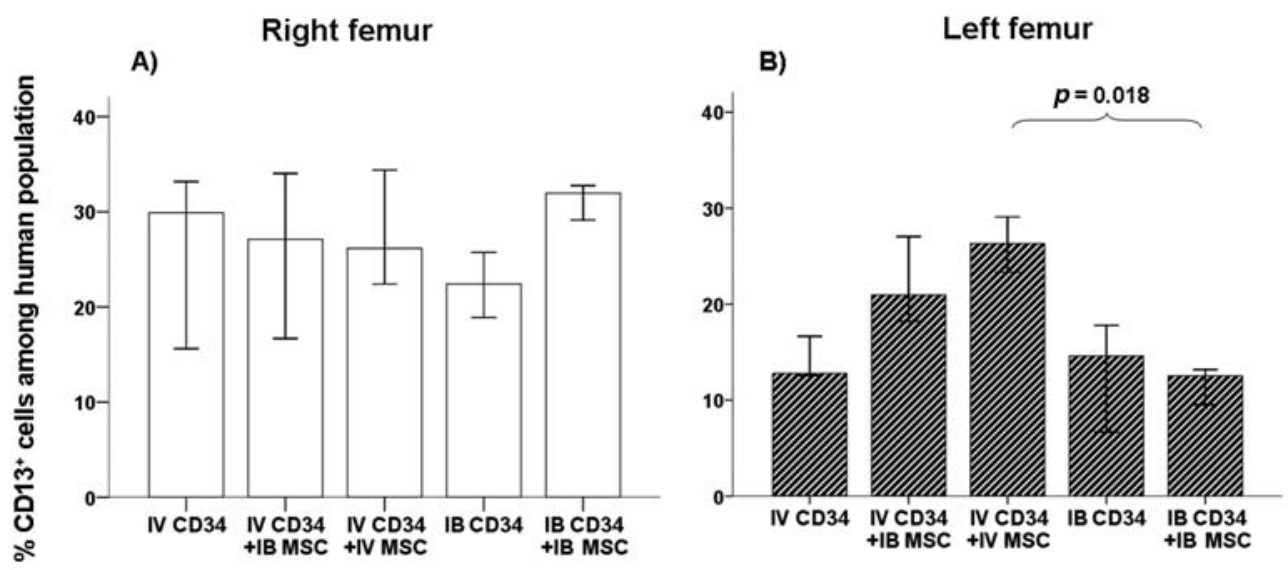

C)

D)
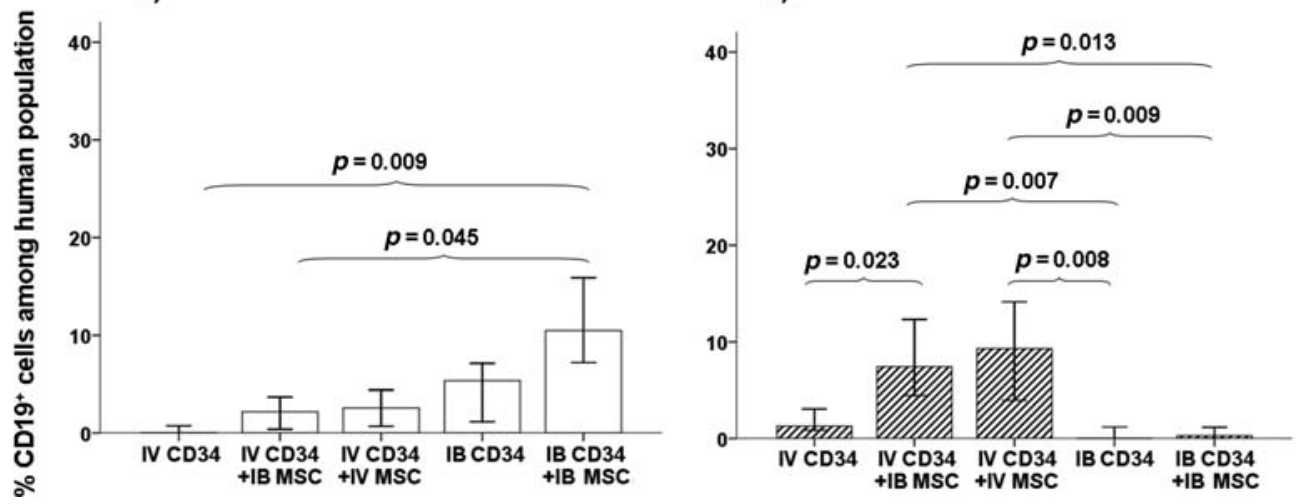

Figure 3. Human hematopoietic subpopulations in NOD/SCID bone marrow at week 3. Percentage of hematopoietic subpopulation of human myeloid cells $\left(\mathrm{CD} 13^{+}\right)(\mathrm{A}, \mathrm{B})$ and lymphoid cells $\left(\mathrm{CD} 19^{+}\right)(\mathrm{C}, \mathrm{D})$ within the total human population in bone marrow from both femurs right (A, C) (injected site) and left (contralateral) (B, D) at week 3 after transplantation. Results expressed as medians (range). $\mathrm{IV}$, intravenous injection; IB, intrabone injection in right femur; CD34, human CD34+ cells; MSC, mesenchymal stem cells. 

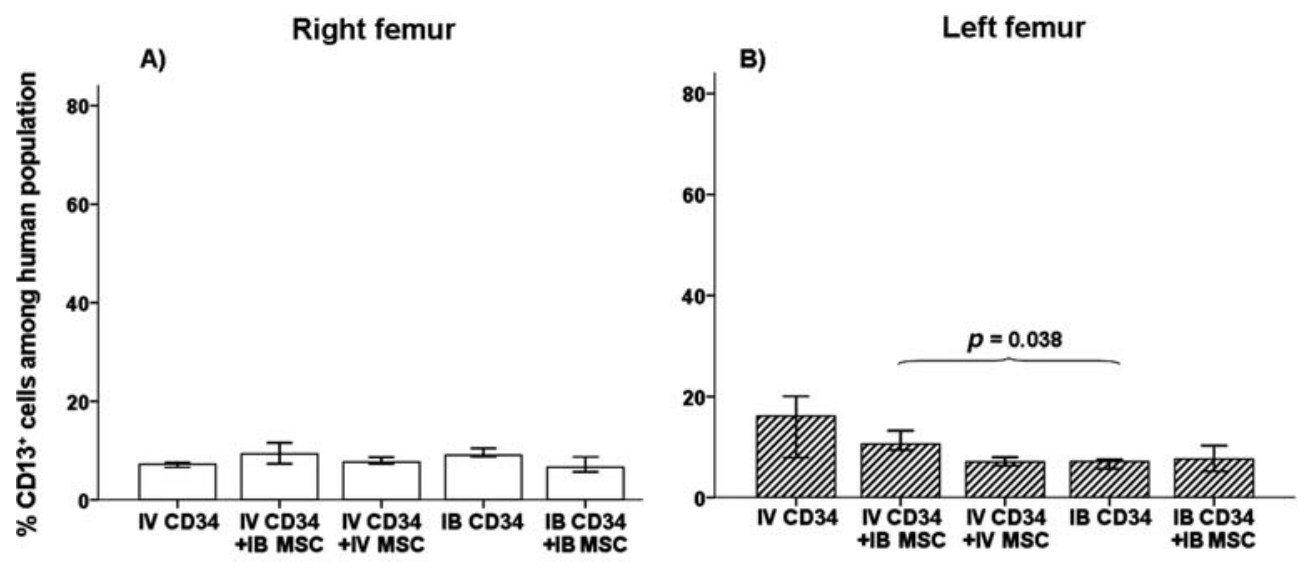

C)

D)
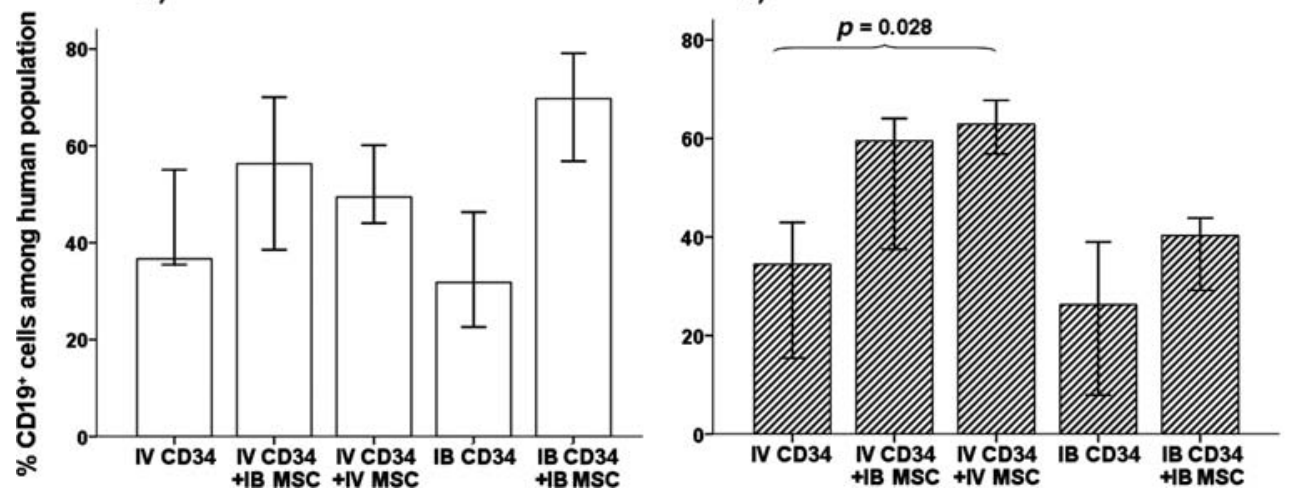

Figure 4. Human hematopoietic subpopulations in NOD/SCID bone marrow at week 6. Percentage of hematopoietic subpopulation of human myeloid cells $\left(\mathrm{CD}^{+} 3^{+}\right)(\mathrm{A}, \mathrm{B})$ and lymphoid cells $\left(\mathrm{CD} 19^{+}\right)(\mathrm{C}, \mathrm{D})$ within the total human population in bone marrow from both femurs, right (A, C) (injected site) and left (contralateral) (B, D), at week 6 after transplantation. Results expressed as medians (range). $\mathrm{IV}$, intravenous injection; IB, intrabone injection in right femur; CD34, human CD34+ cells; MSC, mesenchymal stem cells.

CD19+ population was increased (Fig. 4). In all groups, the percentage of $\mathrm{CD} 19^{+}$cells in both femurs was more than $30 \%$ with the highest level in the left femur of mice receiving both MSCs and HSCs by IV injection (Fig. 4D).

\section{Monitoring of Luciferase-Transduced MSCs in Mice}

Human-transduced MSCs were injected IV or IB in mice at the time of hematopoietic transplantation. The day after IV injection of MSCs, cells were mainly detected in lungs (Fig. 5). In some cases, a focal spot of bioluminescence was observed at the injection site. After IB injection, cells were detected at two levels: lungs and right femurs (injection site). No differences were observed regarding the hematopoietic transplantation route; both groups receiving IB MSC injection with IV or IB CD34 cells had a similar distribution of MSCs.

In all cases, signal from lungs decreased and was not detectable 2 weeks after injection. By contrast, signal from injected femurs could be detected during the whole study period (Fig. 5).

For luciferase signal quantification, defined ROIs were used over the lung and right femur.
The mean peak BLI signal intensities of 1 day after transplantation was $3.1 \times 10^{9}, 5.9 \times 10^{9}$, and $4.6 \times 10^{9}$ photons per second in IV CD34+ IB MSCs, IV CD34+ IV MSCs, and IB CD $34^{+}$IB MSCs, respectively. After 14 days, BLI signal intensities decreased in lungs to background signal intensity (Fig. 6A). However, BLI signal intensities of groups with IB MSC injection was maintained from day +1 to day +42 : $4.8 \times 10^{10}$ to $4.9 \times 10^{9}$ and $4.6 \times 10^{10}$ to $3.1 \times 10^{9}$ in photons per second in IV CD34+ IB MSCs and IB CD34+ IB MSCs, respectively (Fig. 6B).

\section{Detection of Human Cells Within Murine BM}

Six weeks after transplantation, mice were killed, and femurs were fixed for immunofluorescence detection of human cells. Human mitochondria staining allowed detecting human cells and GFP expression and the differentiation between human MSCs $\left(\mathrm{GFP}^{+}\right)$and human hematopoietic cells $\left(\mathrm{GFP}^{-}\right)$.

Human hematopoietic cells in BM were mainly distributed in femur epiphysis showing higher numbers close to the injected site (epiphysis near to the knee) in groups receiving IB injection (Fig. 7A-C). These cells 


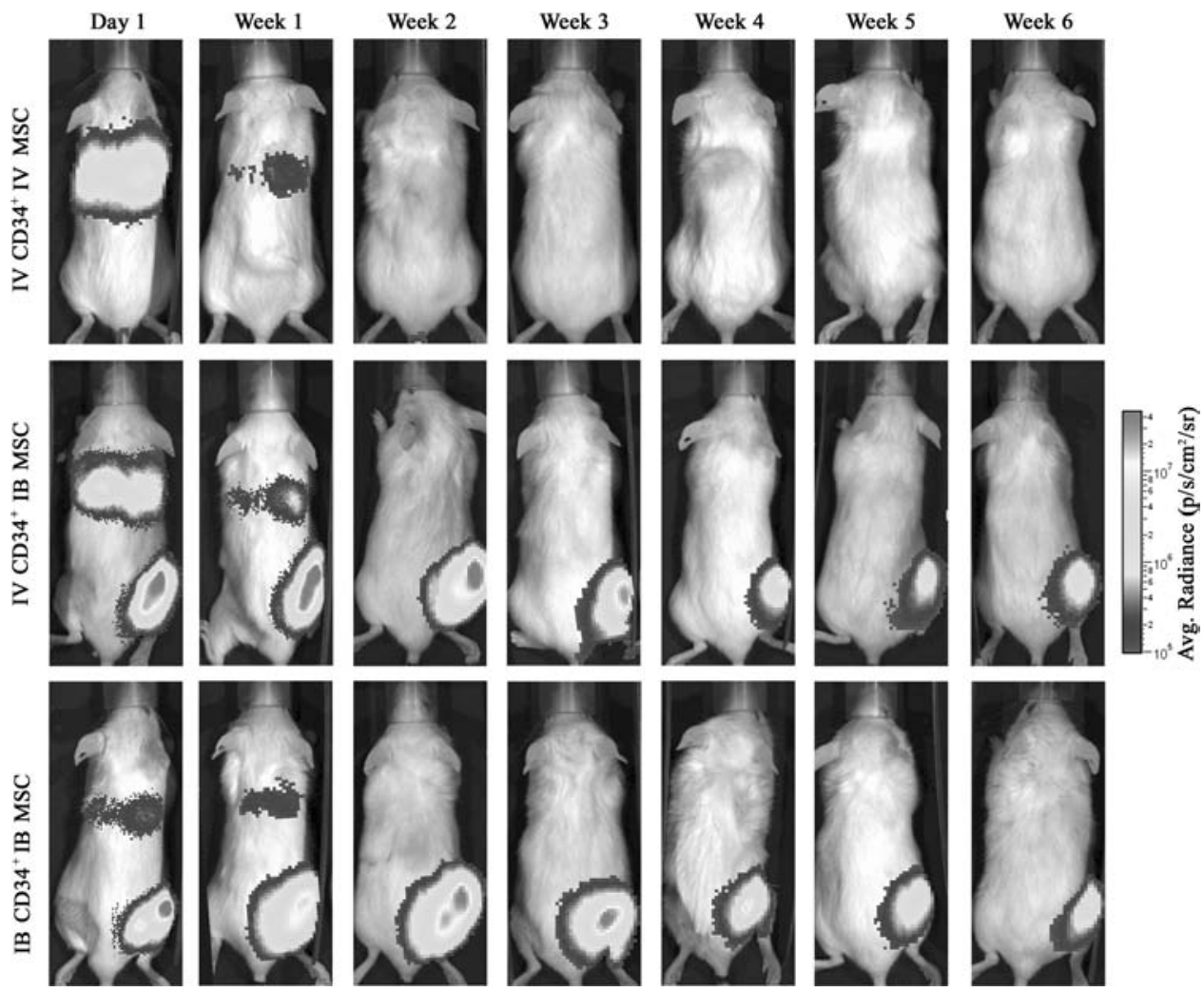

Figure 5. In vivo bioluminescence imaging of NOD/SCID mice. In transplantation groups receiving human MSCs (which expressed luciferase), a weekly imaging of MSC distribution has been done. A representative animal is shown. The reflected light gray scale picture is overlaid by a pseudocolor bioluminescence image (BLI), which allows for allocating the BLI signal to the respective areas shown in the underlying reflected light picture.

formed colonies of round-shaped cells and were growing together close to subendosteal region (Fig. 7D-F). Usually, cases with higher chimerism showed a similar trend of human cells by immunohistochemistry.

Human MSCs were only detected in femurs where they were previously injected and were mainly located in femur epiphysis (Fig. 7A-C), but few GFP-positive cells could be detected in each femur. These cells showed fibroblastic or polygonal shape and could be detected at two levels: some of them were distributed between hematopoietic cells or close to the endosteum, but others showed a clear perivascular distribution (Fig. 7G-I). Blood vessels surrounded by human MSC-derived cells were located in a subendosteal region but not associated with human hematopoietic cells.

\section{DISCUSSION}

Although both strategies have been shown to be useful separately $(6,35,40,55)$, in the current manuscript, we have assessed together the role of intrabone administration of HSC and MSC coadministration in the cord blood xenotransplantation model. To study their homing ability and functional dynamics, MSCs were administered via intrafemoral and were transduced with a luciferaseexpressing vector and thus tracked by bioluminescence.

UCB has emerged as an alternative source of HSCs for transplantation, and several studies have been focused for strategies to enhance UCB engraftment in adult patients $(16,42)$. A higher cryopreserved MNC dose has been associated with faster and higher probability of neutrophil recovery and a higher $\mathrm{CD} 34^{+}$cell dose with better diseasefree survival (19). Since the low number of cells is critical, other strategies that could be used include IB transplantation of UCB cells in order to prevent cell losses $(3,13)$. In a previously reported paper, Massollo et al. (34) demonstrated, using a rat model, that after IB injection, most HSCs escaped to circulating blood as soon as 30 min after their administration, but their first entry contact with the recipient $\mathrm{BM}$ deeply modifies the kinetic and migratory characteristics of donor HSCs increasing their capability to cross the filter of the pulmonary capillary network and improves their homing in BM sites remote from the injection. Our results comparing IV and IB UCB transplantation showed that after IB transplantation, human hematopoietic cell engraftment is not only higher in the injection site but also demonstrates their capability to migrate far from 


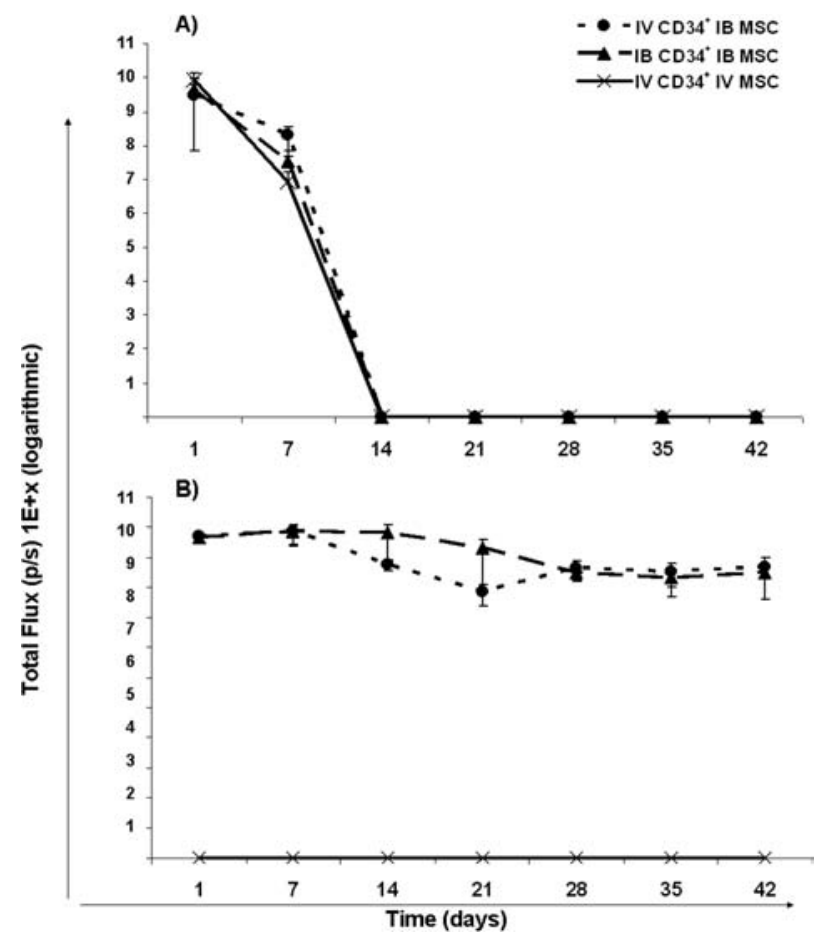

Figure 6. Quantitative analysis of BLI production. The in vivo presence of human MSCs was measured by bioluminescence photometry. In mice lungs, photon flux was going down, and it was not detectable after week 2 (A). By contrast, in previously injected femurs, the signal was reduced during the first 4 weeks, but then its photon emission was maintained (B).

injection sites. This is in accordance with the previous data that suggest that IB injection permits engraftment even without previous irradiation (3).

An alternative to enhance HSC engraftment is to improve $\mathrm{BM}$ microenvironment function. The influence of $\mathrm{BM}$ stroma in hematopoiesis and the axis stromal-derived factor 1/chemokine (C-X-C motif), receptor 4 (SDF1/CXCR4) is a key regulator of both homing and lodgment of HSCs in the niche (38). In this line, improving BM stroma by the coadministration of MSCs is an attractive approach. Several studies have been designed to test this possibility by using MSCs from different sources $(21,30,37)$. In this regard, using placental MSCs in a murine model, Hiwase et al. showed that MSC coinfusion could increase both single and double unit UCB transplantation (21). In the present study, the effect of MSC coinfusion in both transplantation settings, IV or IB injection of HSCs, was tested. We could show in accordance with previous data that when IV transplantation was performed, the addition of MSCs increased human chimerism. When MSC injection route was analyzed, the human engraftment was higher even in femurs not receiving MSCs, demonstrating the capability of MSCs to migrate or to act far from the injection site. The effect of MSCs was higher in the injected femur, and it was more evident 6 weeks after transplantation. Although it was not the aim of the current study, taken into account our results, it would be of interest to perform the xenotransplant experiments with limiting doses of hematopoietic stem cells and also with different doses of MSCs. This should be considered in the future to reinforce the results and to assess the effects of the cell dose in this setting.

It would be also of interest to assess in future works if the same strategy (intrabone administration with or without MSCs) also enhances engraftment of human $\mathrm{PB}$ or BM hematopoietic stem cells, although in $\mathrm{PB}$ or BM HSCT the cell dose is not as relevant as in the cord blood transplantation setting. Nevertheless, it could be useful in the autologous transplantation, especially in those cases of multitreated patients or poor mobilizers.

The next aim of the present work was to know how MSCs exert their effect. Data relating to their engrafting capability in recipient tissues are controversial $(1,27,53)$. In the current study, we tracked the human MSCs until 6 weeks after transplantation by using BLI. The use of BLI for detection of spatial distribution of transplanted MSCs was validated by detecting emitted photons. Sequential evaluation of grafted cell viability was possible with the BLI system since the luciferin-luciferase reaction depends on ATP, and only living cells release photons (23). The first studies tried to find MSC in BM recipients after HSCT $(27,43,53)$. Due to the low number of MSCs present in BM samples, only in cases of patients with osteogenesis imperfecta (27) or a disease with high stromal damage some MSCs from donor origin could be detected (53). It has been reported that, when MSCs have been IV injected, most of them were retained in lungs microvasculature, and they could not be detected in BM (54). These data are in accordance with our results. By bioluminescence, when cells were IV injected, they were only detected during 2 weeks after transplantation. Using a more sensitive technique as immunohistochemistry, 6 weeks after transplantation, human MSCs could not be detected either.

To improve MSC local effects, new trials searching for new routes of administration are being explored (49,51). Local injection of MSCs as intracoronary (57), intrautero (27), kidney (7), or skin injection (48) showed higher engraftment. Taking in account the results in IB injection of hematopoietic cells $(22,44)$, we have considered that this route of delivery could be optimal for MSC administration. In fact, some groups are testing the use of this cells by IB injection in cases of bone damage as multiple myeloma (28). We have shown that, when MSCs were locally injected (in $\mathrm{BM}$ ), they could engraft in recipient BM, and they could be followed for at least 6 weeks.

Their spatial distribution within the BM was also studied. For years, the main niche for HSCs in BM has been the osteoblastic niche $(2,39)$. Due to their osteoblastic differentiation capability, endosteal region has been assumed 

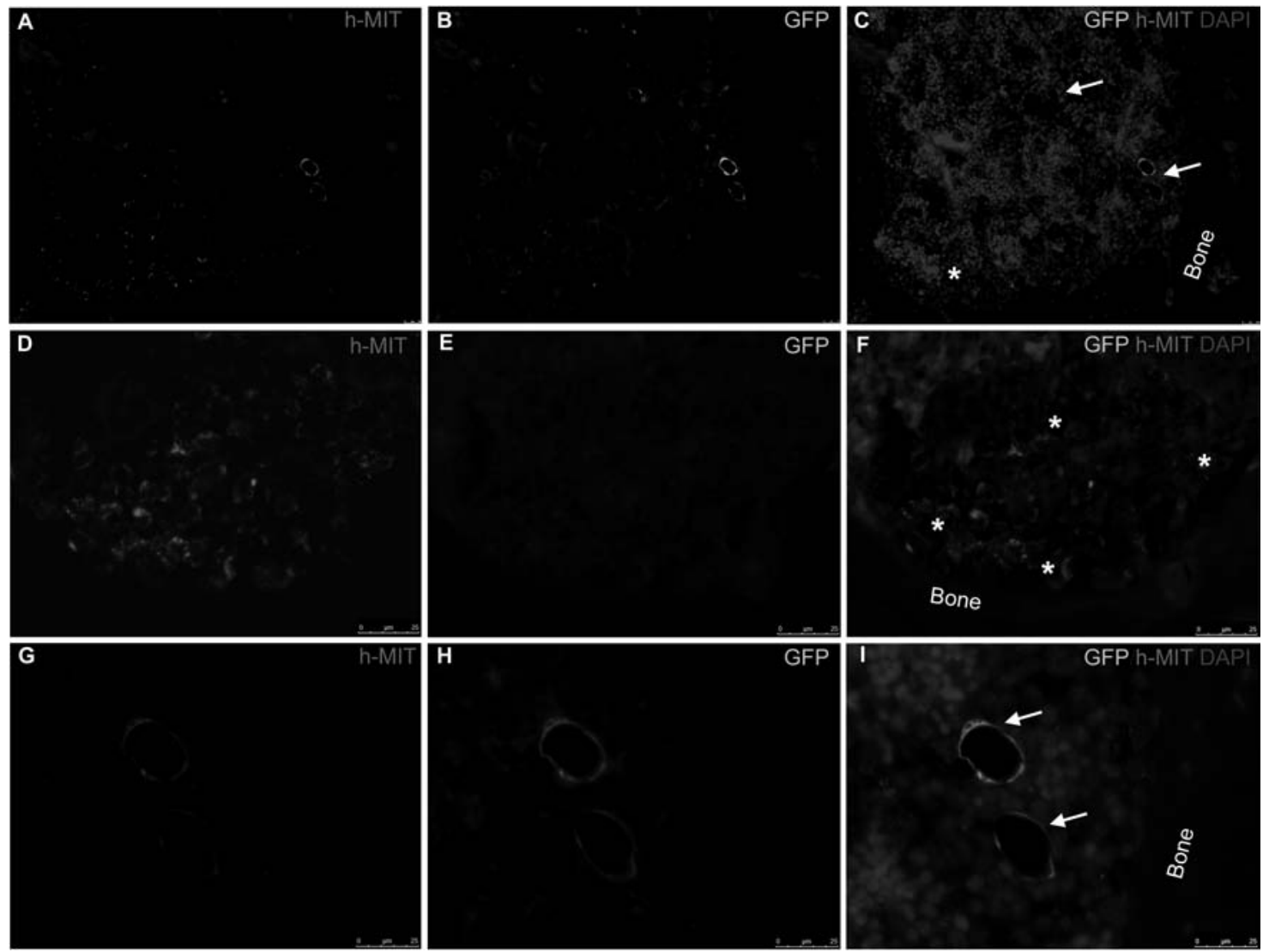

Figure 7. Immunohistochemical analyses of human mitochondria and GFP expression in mice femurs. With the human mitochondria staining, human cells could be detected and green fluorescent protein (GFP) expression and amplification allowed differentiating human MSCs $\left(\mathrm{GFP}^{+}\right)$and human hematopoietic cells $\left(\mathrm{GFP}^{-}\right)$. Six weeks after transplantation, both human cells types, MSCs $(\rightarrow)$ and hematopoietic cells $(*)$, were mainly detected in femur epiphysis $(\mathrm{A}-\mathrm{C})$. Hematopoietic cells were forming cluster of human cells in subendosteal area (A-C, D-F). MSCs could be detected around blood vessels (A-C, G-I). Scale bars: $25 \mu \mathrm{m}$.

as an optimal niche for MSCs (39). We were able to detect human MSCs near the BM endosteum. But recent studies have described another vascular niche, located in BM sinusoids, where HSCs could also be found (14). Some groups have described an MSC population located around these blood vessels $(2,29)$. After the immunofluorescence analysis, we could also find human MSCs, GFP-positive, around blood vessels close to the subendosteal region. This fact is also in accordance with recent data suggesting that endothelial cells might form part of the subendosteal niche and together constitute a common niche where both endosteum and sinusoids contribute to hematopoiesis (2).

In summary, our results show that in our model MSCs could increase hematopoietic engraftment in both IB and IV hematopoietic transplantation. Nevertheless, they were only found in BM recipients after IB injection of MSCs showing a subendosteal and perivascular location within the BM.
ACKNOWLEDGMENTS: We thank Miryam Santos for technical assistance. This study was supported in part by a grant from Gerencia Regional de Salud de Castilla y León (ref. GRS/222/ A/08) and by a grant from Consejería de Educación de la Junta de Castilla y León (ref. HUS003A10-2). S.C. was supported by Junta de Castilla y Leon (FPI grant EDU/1878/2006). The authors declare no conflicts of interest.

\section{REFERENCES}

1. Bartsch, K.; Al-Ali, H.; Reinhardt, A.; Franke, C.; Hudecek, M.; Kamprad, M.; Tschiedel, S.; Cross, M.; Niederwieser, D.; Gentilini, C. Mesenchymal stem cells remain hostderived independent of the source of the stem-cell graft and conditioning regimen used. Transplantation 87:217$221 ; 2009$.

2. Bianco, P. Bone and the hematopoietic niche: A tale of two stem cells. Blood 117:5281-5288; 2011.

3. Bueno, C.; Montes, R.; de la Cueva, T.; Gutierrez-Aranda, I.; Menendez, P. Intra-bone marrow transplantation of human CD34(+) cells into NOD/LtSz-scid IL-2rgamma(null) mice 
permits multilineage engraftment without previous irradiation. Cytotherapy 12:45-49; 2010.

4. Carlotti, F.; Bazuine, M.; Kekarainen, T.; Seppen, J.; Pognonec, P.; Maassen, J. A.; Hoeben, R. C. Lentiviral vectors efficiently transduce quiescent mature 3T3-L1 adipocytes. Mol. Ther. 9:209-217; 2004.

5. Carrancio, S.; Lopez-Holgado, N.; Sanchez-Guijo, F. M.; Villaron, E.; Barbado, V.; Tabera, S.; Diez-Campelo, M.; Blanco, J.; San Miguel, J. F.; Del Canizo, M. C. Optimization of mesenchymal stem cell expansion procedures by cell separation and culture conditions modification. Exp. Hematol. 36:1014-1021; 2008.

6. Castello, S.; Podesta, M.; Menditto, V. G.; Ibatici, A.; Pitto, A.; Figari, O.; Scarpati, D.; Magrassi, L.; Bacigalupo, A.; Piaggio, G.; Frassoni, F. Intra-bone marrow injection of bone marrow and cord blood cells: An alternative way of transplantation associated with a higher seeding efficiency. Exp. Hematol. 32:782-787; 2004.

7. Chen, Y. T.; Sun, C. K.; Lin, Y. C.; Chang, L. T.; Chen, Y. L.; Tsai, T. H.; Chung, S. Y.; Chua, S.; Kao, Y. H.; Yen, C. H.; Shao, P. L.; Chang, K. C.; Leu, S.; Yip, H. K. Adipose-derived mesenchymal stem cell protects kidneys against ischemiareperfusion injury through suppressing oxidative stress and inflammatory reaction. J. Transl. Med. 9:51; 2011.

8. Del Canizo, M. C.; Fernandez, M. E.; Lopez, A.; Vidriales, B.; Villaron, E.; Arroyo, J. L.; Ortuno, F.; Orfao, A.; San Miguel, J. F. Immunophenotypic analysis of myelodysplastic syndromes. Haematologica 88:402-407; 2003.

9. Dominici, M.; Le Blanc, K.; Mueller, I.; Slaper-Cortenbach, I.; Marini, F.; Krause, D.; Deans, R.; Keating, A.; Prockop, D.; Horwitz, E. Minimal criteria for defining multipotent mesenchymal stromal cells. The International Society for Cellular Therapy position statement. Cytotherapy 8:315317; 2006.

10. Fernandez, M. N. Improving the outcome of cord blood transplantation: Use of mobilized HSC and other cells from third party donors. Br. J. Haematol. 147:161-176; 2009.

11. Follenzi, A.; Ailles, L. E.; Bakovic, S.; Geuna, M.; Naldini, L. Gene transfer by lentiviral vectors is limited by nuclear translocation and rescued by HIV-1 pol sequences. Nat. Genet. 25:217-222; 2000.

12. Follenzi, A.; Naldini, L. HIV-based vectors. Preparation and use. Methods Mol. Med. 69:259-274; 2002.

13. Frassoni, F.; Gualandi, F.; Podesta, M.; Raiola, A. M.; Ibatici, A.; Piaggio, G.; Sessarego, M.; Sessarego, N.; Gobbi, M.; Sacchi, N.; Labopin, M.; Bacigalupo, A. Direct intrabone transplant of unrelated cord-blood cells in acute leukaemia: A phase I/II study. Lancet Oncol. 9:831-839; 2008.

14. Garrett, R. W.; Emerson, S. G. Bone and blood vessels: The hard and the soft of hematopoietic stem cell niches. Cell Stem Cell 4:503-506; 2009.

15. Geuze, R. E.; Prins, H. J.; Oner, F. C.; van der Helm, Y. J.; Schuijff, L. S.; Martens, A. C.; Kruyt, M. C.; Alblas, J.; Dhert, W. J. Luciferase labeling for multipotent stromal cell tracking in spinal fusion versus ectopic bone tissue engineering in mice and rats. Tissue Eng. Part A 16:3343-3351; 2010.

16. Gluckman, E.; Ruggeri, A.; Volt, F.; Cunha, R.; Boudjedir, K.; Rocha, V. Milestones in umbilical cord blood transplantation. Br. J. Haematol. 154:441-447; 2011.

17. Gonzalo-Daganzo, R.; Regidor, C.; Martin-Donaire, T.; Rico, M. A.; Bautista G.; Krsnik, I.; Fores, R.; Ojeda, E.; Sanjuan, I.; Garcia-Marco, J. A.; Navarro, B.; Gil, S.;
Sanchez, R.; Panadero, N.; Gutierrez, Y.; Garcia-Berciano, M.; Perez, N.; Millan, I.; Cabrera, R.; Fernandez, M. N. Results of a pilot study on the use of third-party donor mesenchymal stromal cells in cord blood transplantation in adults. Cytotherapy 11:278-288; 2009.

18. Guo, C. J.; Gao, Y.; Hou, D.; Shi, D. Y.; Tong, X. M.; Shen, D.; Xi, Y. M.; Wang, J. F. Preclinical transplantation and safety of HS/PCs expanded from human umbilical cord blood. World J. Stem Cells 3:43-52; 2011.

19. Herr, A. L.; Kabbara, N.; Bonfim, C. M.; Teira, P.; Locatelli, F.; Tiedemann, K.; Lankester, A.; Jouet, J. P.; Messina, C.; Bertrand, Y.; Diaz de Heredia, C.; Peters, C.; Chaves, W.; Nabhan, S. K.; Ionescu, I.; Gluckman, E.; Rocha, V. Longterm follow-up and factors influencing outcomes after related HLA-identical cord blood transplantation for patients with malignancies: An analysis on behalf of Eurocord-EBMT. Blood 116:1849-1856; 2010.

20. Hesselton, R. M.; Greiner, D. L.; Mordes, J. P.; Rajan, T. V.; Sullivan, J. L.; Shultz, L. D. High levels of human peripheral blood mononuclear cell engraftment and enhanced susceptibility to human immunodeficiency virus type 1 infection in NOD/LtSz-scid/scid mice. J. Infect. Dis. 172:974-982; 1995.

21. Hiwase, S. D.; Dyson, P. G.; To, L. B.; Lewis, I. D. Cotransplantation of placental mesenchymal stromal cells enhances single and double cord blood engraftment in nonobese diabetic/severe combined immune deficient mice. Stem Cells 27:2293-2300; 2009.

22. Ikehara, S. Intra-bone marrow-bone marrow transplantation: A new strategy for treatment of stem cell disorders. Ann. N.Y. Acad. Sci. 1051:626-634; 2005.

23. Jang, K. S.; Lee, K. S.; Yang, S. H.; Jeun, S. S. In vivo tracking of transplanted bone marrow-derived mesenchymal stem cells in a murine model of stroke by bioluminescence imaging. J. Korean Neurosurg. Soc. 48:391-398; 2010.

24. Kanathezhath, B.; Walters, M. C. Umbilical cord blood transplantation for thalassemia major. Hematol. Oncol. Clin. North. Am. 24:1165-1177; 2010.

25. Kanda, J.; Rizzieri, D. A.; Gasparetto, C.; Long, G. D.; Chute, J. P.; Sullivan, K. M.; Morris, A.; Smith, C. A.; Hogge, D. E.; Nitta, J.; Song, K.; Niedzwiecki, D.; Chao, N. J.; Horwitz, M. E. Adult dual umbilical cord blood transplantation using myeloablative total body irradiation (1350 cGy) and fludarabine conditioning. Biol. Blood Marrow Transplant. 17:867-874; 2011.

26. Karp, J. M.; Leng Teo, G. S. Mesenchymal stem cell homing: The devil is in the details. Cell Stem Cell 4:206-216; 2009.

27. Le Blanc, K.; Gotherstrom, C.; Ringden, O.; Hassan, M.; McMahon, R.; Horwitz, E.; Anneren, G.; Axelsson, O.; Nunn, J.; Ewald, U.; Norden-Lindeberg, S.; Jansson, M.; Dalton, A.; Astrom, E.; Westgren, M. Fetal mesenchymal stem-cell engraftment in bone after in utero transplantation in a patient with severe osteogenesis imperfecta. Transplantation 79:1607-1614; 2005.

28. Li, X.; Ling, W.; Pennisi, A.; Wang, Y.; Khan, S.; Heidaran, M.; Pal, A.; Zhang, X.; He, S.; Zeitlin, A.; Abbot, S.; Faleck, H.; Hariri, R.; Shaughnessy, Jr., J. D.; van Rhee, F.; Nair, B.; Barlogie, B.; Epstein, J.; Yaccoby, S. Human placentaderived adherent cells prevent bone loss, stimulate bone formation, and suppress growth of multiple myeloma in bone. Stem Cells 29:263-273; 2011.

29. Lozito, T. P.; Kuo, C. K.; Taboas, J. M.; Tuan, R. S. Human mesenchymal stem cells express vascular cell phenotypes 
upon interaction with endothelial cell matrix. J. Cell. Biochem. 107:714-722; 2009.

30. Macmillan, M. L.; Blazar, B. R.; DeFor, T. E.; Wagner, J. E. Transplantation of ex-vivo culture-expanded parental haploidentical mesenchymal stem cells to promote engraftment in pediatric recipients of unrelated donor umbilical cord blood: Results of a phase I-II clinical trial. Bone Marrow Transplant. 43:447-454; 2009.

31. Madureira, A. B.; Eapen, M.; Locatelli, F.; Teira, P.; Zhang, M. J.; Davies, S. M.; Picardi, A.; Woolfrey, A.; Chan, K. W.; Socie, G.; Vora, A.; Bertrand, Y.; Sales-Bonfim, C. M.; Gluckman, E.; Niemeyer, C.; Rocha, V. Analysis of risk factors influencing outcome in children with myelodysplastic syndrome after unrelated cord blood transplantation. Leukemia 25:449-454; 2011.

32. Majhail, N. S.; Brunstein, C. G.; Shanley, R.; Sandhu, K.; McClune, B.; Oran, B.; Warlick, E. D.; Wagner, J. E.; Weisdorf, D. J. Reduced-intensity hematopoietic cell transplantation in older patients with AML/MDS: Umbilical cord blood is a feasible option for patients without HLAmatched sibling donors. Bone Marrow Transplant. 47:494498; 2012.

33. Marigo, I.; Dazzi, F. The immunomodulatory properties of mesenchymal stem cells. Semin. Immunopathol. 33:593602; 2011.

34. Massollo, M.; Podesta, M.; Marini, C.; Morbelli, S.; Cassanelli, C.; Pinto, V.; Ubezio, G.; Curti, G.; Uccelli, A.; Frassoni, F.; Sambuceti, G. Contact with the bone marrow microenvironment readdresses the fate of transplanted hematopoietic stem cells. Exp. Hematol. 38:968-977; 2010.

35. Mazurier, F.; Doedens, M.; Gan, O. I.; Dick, J. E. Rapid myeloerythroid repopulation after intrafemoral transplantation of NOD-SCID mice reveals a new class of human stem cells. Nat. Med. 9:959-963; 2003.

36. Mendez-Ferrer, S.; Michurina, T. V.; Ferraro, F.; Mazloom, A. R.; Macarthur, B. D.; Lira, S. A.; Scadden, D. T.; Ma'ayan, A.; Enikolopov, G. N.; Frenette, P. S. Mesenchymal and haematopoietic stem cells form a unique bone marrow niche. Nature 466:829-834; 2010.

37. Meuleman, N.; Tondreau, T.; Ahmad, I.; Kwan, J.; Crokaert, F.; Delforge, A.; Dorval, C.; Martiat, P.; Lewalle, P.; Lagneaux, L.; Bron, D. Infusion of mesenchymal stromal cells can aid hematopoietic recovery following allogeneic hematopoietic stem cell myeloablative transplant: A pilot study. Stem Cells Dev. 18:1247-1252; 2009.

38. Mohty, M.; Ho, A. D. In and out of the niche: Perspectives in mobilization of hematopoietic stem cells. Exp. Hematol. 39:723-729; 2011.

39. Nakamura, Y.; Arai, F.; Iwasaki, H.; Hosokawa, K.; Kobayashi, I.; Gomei, Y.; Matsumoto, Y.; Yoshihara, H.; Suda, T. Isolation and characterization of endosteal niche cell populations that regulate hematopoietic stem cells. Blood 116:1422-1432; 2010.

40. Noort, W. A.; Kruisselbrink, A. B.; in't Anker, P. S.; Kruger, M.; van Bezooijen, R. L.; de Paus, R. A.; Heemskerk, M. H.; Lowik, C. W.; Falkenburg, J. H.; Willemze, R.; Fibbe, W. E. Mesenchymal stem cells promote engraftment of human umbilical cord blood-derived CD34(+) cells in NOD/SCID mice. Exp. Hematol. 30:870-878; 2002.

41. Oran, B.; Wagner, J. E.; DeFor, T. E.; Weisdorf, D. J.; Brunstein, C. G. Effect of conditioning regimen intensity on acute myeloid leukemia outcomes after umbilical cord blood transplantation. Biol. Blood Marrow Transplant. 17:1327-1334; 2011.

42. Petropoulou, A. D.; Rocha, V. Risk factors and options to improve engraftment in unrelated cord blood transplantation. Stem Cells Int. 2011:610514; 2011.

43. Pozzi, S.; Lisini, D.; Podesta, M.; Bernardo, M. E.; Sessarego, N.; Piaggio, G.; Cometa, A.; Giorgiani, G.; Mina, T.; Buldini, B.; Maccario, R.; Frassoni, F.; Locatelli, F. Donor multipotent mesenchymal stromal cells may engraft in pediatric patients given either cord blood or bone marrow transplantation. Exp. Hematol. 34:934-942; 2006.

44. Ramirez, P. A.; Wagner, J. E.; Brunstein, C. G. Going straight to the point: Intra-BM injection of hematopoietic progenitors. Bone Marrow Transplant. 45:1127-1133; 2010.

45. Rocha, V.; Crotta, A.; Ruggeri, A.; Purtill, D.; Boudjedir, K.; Herr, A. L.; Ionescu, I.; Gluckman, E. Double cord blood transplantation: Extending the use of unrelated umbilical cord blood cells for patients with hematological diseases. Best Pract. Res. Clin. Haematol. 23:223-229; 2010.

46. Sanchez-Guijo, F. M.; Blanco, J. F.; Cruz, G.; Muntion, S.; Gomez, M.; Carrancio, S.; Lopez-Villar, O.; Barbado, M. V.; Sanchez-Abarca, L. I.; Blanco, B.; Brinon, J. G.; del Canizo, M. C. Multiparametric comparison of mesenchymal stromal cells obtained from trabecular bone by using a novel isolation method with those obtained by iliac crest aspiration from the same subjects. Cell Tissue Res. 336:501-507; 2009.

47. Tabera, S.; Perez-Simon, J. A.; Diez-Campelo, M.; SanchezAbarca, L. I.; Blanco, B.; Lopez, A.; Benito, A.; Ocio, E.; Sanchez-Guijo, F. M.; Canizo, C.; San Miguel, J. F. The effect of mesenchymal stem cells on the viability, proliferation and differentiation of B-lymphocytes. Haematologica 93:1301-1309; 2008.

48. Tark, K. C.; Hong, J. W.; Kim, Y. S.; Hahn, S. B.; Lee, W. J.; Lew, D. H. Effects of human cord blood mesenchymal stem cells on cutaneous wound healing in leprdb mice. Ann. Plast. Surg. 65:565-572; 2010.

49. Trouche, E.; Girod, F. S.; Mias, C.; Ceccaldi, C.; Tortosa, F.; Seguelas, M. H.; Calise, D.; Parini, A.; Cussac, D.; Sallerin, B. Evaluation of alginate microspheres for mesenchymal stem cell engraftment on solid organ. Cell Transplant. 19: 1623-1633; 2010.

50. Tung, S. S.; Parmar, S.; Robinson, S. N.; de Lima, M.; Shpall, E. J. Ex vivo expansion of umbilical cord blood for transplantation. Best Pract. Res. Clin. Haematol. 23:245257; 2010.

51. van Velthoven, C. T.; Kavelaars, A.; van Bel, F.; Heijnen, C. J. Nasal administration of stem cells: A promising novel route to treat neonatal ischemic brain damage. Pediatr. Res. 68:419-422; 2010.

52. Verlinden, S. F.; van Es, H. H.; van Bekkum, D. W. Serial bone marrow sampling for long-term follow up of human hematopoiesis in NOD/SCID mice. Exp. Hematol. 26:627630; 1998.

53. Villaron, E. M.; Almeida, J.; Lopez-Holgado, N.; Alcoceba, M.; Sanchez-Abarca, L. I.; Sanchez-Guijo, F. M.; Alberca, M.; Perez-Simon, J. A.; San Miguel, J. F.; Del Canizo, M. C. Mesenchymal stem cells are present in peripheral blood and can engraft after allogeneic hematopoietic stem cell transplantation. Haematologica 89:1421-1427; 2004.

54. Wang, W.; Jiang, Q.; Zhang, H.; Jin, P.; Yuan, X.; Wei, $\mathrm{Y}$; $\mathrm{Hu}, \mathrm{S}$. Intravenous administration of bone marrow 
mesenchymal stromal cells is safe for the lung in a chronic myocardial infarction model. Regen. Med. 6:179-190; 2011.

55. Yahata, T.; Ando, K.; Sato, T.; Miyatake, H.; Nakamura, Y.; Muguruma, Y.; Kato, S.; Hotta, T. A highly sensitive strategy for SCID-repopulating cell assay by direct injection of primitive human hematopoietic cells into NOD/SCID mice bone marrow. Blood 101:2905-2913; 2003.
56. Zhong, X. Y.; Zhang, B.; Asadollahi, R.; Low, S. H.; Holzgreve, W. Umbilical cord blood stem cells: What to expect. Ann. N.Y. Acad. Sci. 1205:17-22; 2010.

57. Zhu, H.; Song, X.; Jin, L. J.; Jin, P.; Guan, R.; Liu, X.; Li, X. Q. Comparison of intra-coronary cell transplantation after myocardial infarction: Autologous skeletal myoblasts versus bone marrow mesenchymal stem cells. J. Int. Med. Res. 37:298-307; 2009. 